\title{
Comparison of immunogenicity and safety outcomes of a malaria vaccine FMP013/ALFQ in rhesus macaques (Macaca mulatta) of Indian and Chinese origin
}

Monica L. Martin', Alexis A. Bitzer², Andrew Schrader ${ }^{1}$, Elke S. Bergmann-Leitner ${ }^{3}$, Kim Soto², Xiaoyan Zou Zoltan Beck ${ }^{5,6}$, Gary R. Matyas ${ }^{5}$ and Sheetij Dutta ${ }^{*}$

\begin{abstract}
Background: Indian-origin rhesus (InR) are preferred for research, but strict export restrictions continue to limit their use. Chinese-origin rhesus (ChR), although easier to procure, are genetically distinct from InR and differ in their immune response to infectious agents, such as the Simian Immunodeficiency Virus. The most advanced malaria vaccine, RTS,S (GlaxoSmithKline), is based on the circumsporozoite protein (CSP) of Plasmodium falciparum. The efficacy of RTS,S vaccine in the field remains low and short-lived; efforts are underway to improve CSP-based vaccines. Rhesus models can accelerate preclinical down-selection of the next generation of malaria vaccines. This study was used to determine if the safety and immunogenicity outcomes following vaccination with a CSP vaccine would differ in the InR and ChR models, given the genetic differences between the two sub-populations of rhesus.

Methods: The FMP013 vaccine, was composed of nearly full-length soluble P. falciparum CSP produced in Escherichia coli and was adjuvanted with the Army liposomal formulation (ALFQ). Three doses of the vaccine were administered in InR and ChR $(n=6)$ at 1 -month intervals and the antibody and T cell responses were assessed.

Results: Local and systemic toxicity profile of FMP013 vaccine in $\ln R$ and ChR were similar and they revealed that the FMP013 vaccine was safe and caused only mild and transient inflammatory adverse reactions. Following the first 2 vaccines, there was a slower acquisition of antibodies to the CSP repeat region in ChR. However after the 3rd vaccination the titers in the two models were comparable. The ChR group repeat-specific antibodies had higher avidity and ChR group showed higher inhibition of liver stage development activity compared to InR. There was no difference in T-cell responses to the FMP013 vaccine between the two models.

Conclusions: A difference in the quality of serological responses was detected between the two sub-populations of rhesus. However, both models confirmed that FMP013/ALFQ vaccine was safe, highly immunogenic, elicited functional antibodies and T-cell responses. Overall, the data suggests that rhesus of Indian and Chinese origins can be interchangeably used to compare the safety and immunogenicity of next-generation of malaria vaccines and adjuvants.
\end{abstract}

Keywords: Circumsporozoite protein, CSP, Rhesus, Chinese origin, Indian origin, Macaque, Malaria, ALFQ, FMP013

\footnotetext{
*Correspondence: sheetij.dutta.civ@mail.mil

2 Structural Biologics Laboratory, Malaria Biologics Branch, Walter Reed

Army Institute of Research, Silver Spring, MD 20910, USA

Full list of author information is available at the end of the article
} 


\section{Background}

Malaria infects over 200 million individuals every year, and despite the reduction in morbidity and mortality in the last 20 years, more than 400,000 deaths are reported annually $[1,2]$.

Plasmodium falciparum is one of the species that is most commonly associated with the severe and fatal form of malaria that is prevalent in sub-Saharan Africa [1]. RTS,S (GlaxoSmithKline Vaccines, Rixensart, Belgium) is a recombinant malaria antigen based on the circumsporozoite protein (CSP) of $P$. falciparum. The CSP portion of RTS,S consists of 19 NPNA repeating units and the $\mathrm{C}$-terminal region while the remainder of the protein is the hepatitis B surface antigen [3, 4]. While, the NPNA repeats are highly conserved across all $P$. falciparum strains, the $\mathrm{C}$-terminal region contains polymorphic residues, which could be one of the reasons why a monovalent CSP vaccine, such as RTS,S, confers partial protection against diverse parasite strains prevalent in endemic areas [5]. RTS,S is formulated in the potent adjuvant AS01B, that contains two immune-stimulators: monophosphoryl-lipid A and QS-21. Vaccination with RTS,S/AS01 induces high level of protection against controlled human malaria infection however, in Phase 3 trials, RTS,S/AS01 induces less than 50\% protection against natural infection [6, 7]. In 2015, a paediatric formulation of RTS,S/AS01E (Mosquirix ${ }^{\mathrm{TM}}$ ) received regulatory approval, and is in pilot studies in three African countries, to determine its effectiveness in malaria control when deployed by the public health system [8].

As a step towards improving the efficacy of RTS,S/ AS01, Walter Reed Army Institute of Research has developed a CSP-based antigen, FMP013, which is a soluble protein vaccine aimed at broadening the immunity to epitopes not present within the RTS,S construct as it also contains the N-terminal region along with junctional epitopes and minor repeats of CSP [9, 10]. FMP013 was formulated in a potent adjuvant, the Army Liposomal Formulation containing QS-21 (ALFQ). The immunestimulants present within ALFQ, 3D-PHAD ${ }^{\mathrm{TM}}$ (TLR-4 agonist) and QS-21 (modulator of innate immunity) have been shown to be critical for the optimal immunogenicity of FMP013 vaccine in mice and rhesus models [10-12].

Since first reported in 1995, it took 15 years and millions of dollars to conduct the series of clinical trials that led to recently initiated pilot implementation of Mosquirix $^{\mathrm{TM}}$, in Africa [13]. With limited resources and high regulatory costs, a next-generation malaria vaccine would need to rely heavily upon animal models to accelerate progression. Mouse models are excellent for understanding how innate and acquired immunity against the malaria parasite protects and there are transgenic parasites that allow the evaluation of protective efficacy of human malaria vaccines in mice [14]. Mouse models, although useful, are not a reliable predictor of human malaria vaccine outcomes as was shown in a mouse and rhesus comparative immunogenicity study using two CSP-based vaccines [15]. Rhesus model also has limitations, as rhesus-specific immunological reagents are not well characterized; yet it is argued that for vaccine candidates, such as CSP, rhesus ought to remain on the critical path of de-risking second-generation CSP formulations before transitioning to human vaccines trials [15]. Historically, the Indian origin rhesus (InR) has been a preferred model for research based on the published data $[16,17]$. However, due to a 1978 ban on exporting rhesus [18], InR research in the United States, has relied exclusively on purpose-bred colonies.

An alternative to InR are wild-caught and colony-bred rhesus of Chinese origin (ChR). ChR males are heavier, longer, and taller than InR males $[19,20]$, and they differ from InR in behaviour, physiology and temperament [19, 21]. At the genetic level, these two populations have been differentiated by single nucleotide polymorphisms and mitochondrial DNA sequences $[18,22]$. ChR populations are known to be more genetically diverse than InR [23] and this difference has been shown to affect some disease and vaccine outcomes between the two models. For example, simian immunodeficiency virus (SIV) infected ChR had higher CD4+ cell counts and lower viral loads than InR [23, 24]. ChR are believed to better mimic the slower progression of human immunodeficiency virus (HIV) infection in humans [25] and have become useful models for HIV vaccine research [23, 26]. Among other factors, the difference in SIV infection profile has been correlated with a difference in the copy number of an HIV-suppressive chemokine CCL3L and a more Th1biased $\mathrm{T}$ cell response in ChR $[27,28]$.

In light of easier access and availability, malaria vaccine developers would need to increasingly rely on the $\mathrm{ChR}$ model. To determine if these observed differences in SIV infection profile also extended to malaria vaccine outcomes, the FMP013 vaccine adjuvanted with ALFQ was compared head-to-head in the InR and ChR models. Important differences were observed in antibody quality between the two models. While these immunological differences between the two models need to be factored into the design and interpretation of future rhesus trials, the data suggests that $\mathrm{ChR}$ and InR could be used interchangeably for malaria vaccine down-selection studies.

\section{Methods}

\section{Rhesus}

Adult rhesus macaques of Indian (InR) and Chinese (ChR) origin, were housed at the Walter Reed Army Institute of Research (WRAIR) animal facility, and used 
under an IACUC-approved protocol. InR were colony bred in Alice, Texas, their ages ranged from 8 to 11 years old. The ChR, also in the 8-12 years age-range, were imported from China over several months from March 2013 to November 2013. Capture sites or breeding sites of $\mathrm{ChR}$ were unknown. ChR were housed in separate rooms from the InR and all monkeys were tested seronegative for macacine herpesvirus 1 , measles, simian retrovirus, simian immunodeficiency virus (SIV), simian T cell leukemia virus, and tuberculin skin test. Additionally, all macaques were pre-screened for pre-existing antibodies against $P$. falciparum CSP and antibodies against the immune-stimulator monophosphoryl lipid-A. Animals were pair-housed with same sex and conspecific origins, fed a commercial diet (Lab Diet 5038, Purina Mills International), provided water ad libitum, and supplemented with a variety of fresh fruits and vegetables. Environmental enrichment was provided in accordance with WRAIR Veterinary Service Program standard operating procedures. Animal cages were cleaned daily and sanitized bimonthly. Automatic lighting was on a 12:12 h cycle.

\section{Vaccines and adjuvant}

The FMP013 was cGMP grade soluble Escherichia coli product containing the $P$. falciparum CSP $\mathrm{N}$-terminal region, 19 NPNA and 3 NVDP repeats and the C-terminal region [11]. Vaccine was adjuvanted with $1 \mathrm{~mL}$ of ALFQ containing: $200 \mu \mathrm{g}$ 3D-PHAD ${ }^{\mathrm{TM}}$ (Avanti Polar Lipids, Alabaster, CA) and $100 \mu \mathrm{g}$ QS-21 (Desert King, San Diego, CA) immune modulators [11]. The formulation was mixed on a rotary platform for $1 \mathrm{~h}$ prior to administration.

\section{Vaccination}

Age, sex, and weight of the monkeys were approximately matched across groups (Additional file 1: Table S1). Six $\mathrm{ChR}$ were all females and InR had 3 males and 3 females. Animals were sedated using Ketamine $11 \mathrm{mg} / \mathrm{kg}$ and Acepromazine $0.55 \mathrm{mg} / \mathrm{kg}$. Once sedated the vaccine injection site was shaved, cleaned and disinfected with $70 \%$ isopropyl alcohol. The InR and ChR $(n=6)$ received three vaccines of $40 \mu \mathrm{g}$ FMP013, intramuscular in alternating left and right thigh, on days 0,28 , and 60 .

\section{Safety and tolerability}

Animals were sedated for all exams and blood collections. Heart rate, respiration, body weights, and rectal temperatures were recorded on days $1,3,7,14,28$ (D1, D3, D7, D14, and D28) post vaccine. Injection sites were examined and compared to baseline at D1, D3, and D7 post vaccine administration. For immunization site reactogenicity, a grading scale $(1=$ diffuse pink or mild swelling or mild, $2=$ diffuse red flush or moderate swelling or moderate, $3=$ marked red flush) was used [29]. Blood samples were taken 2 weeks before the first dose and then on D1, D3, D7 for toxicology (Additional file 1: Table S2A, B). Sera were collected for ELISA at 2 week following each vaccination. All samples were collected from the femoral vein using a Vacutainer ${ }^{\mathrm{TM}}$ tubes (Becton-Dickinson, Franklin Lakes, NJ).

\section{ELISA}

Direct and avidity ELISA were performed by the International Malaria Serology Reference Center (WRAIR, Silver Spring, MD) against the FMP013 and (NANP) ${ }_{6} \mathrm{C}$ repeat peptide [14]. Secondary antibody used was HRP conjugated goat anti-human. ELISA titer was defined as the serum dilution that resulted in optical density (OD) of 1.0 as predicted by a four-parameter curve fitting equation (Biotek, Winooski, VT). Avidity ELISA was conducted similar to above using $4 \mathrm{M}$ urea wash for $10 \mathrm{~min}$ following the incubation of the primary antibody to remove low affinity antibodies. ELISA plates were developed and avidity index was calculated as the ratio of titers obtained after washing the plate with urea or with PBS [30].

\section{ILSDA}

Whole serum was tested by inhibition of sporozoite development assay, ILSDA [14]. Briefly, the P. falciparum NF54 strain sporozoites obtained from salivary gland dissections of infected Anopheles mosquitoes were mixed with a positive control monoclonal antibody NFS1 or polyclonal rhesus serum at two dilutions (1:200 and 1:300) and incubated at room temperature for $20 \mathrm{~min}$. The sporozoite-antibody mixtures were then introduced into the wells containing cryopreserved human hepatocytes (BioReclamation IVT, Baltimore, MD) and incubated at $37^{\circ} \mathrm{C}$ for $3 \mathrm{~h}$ to allow sporozoites to infect hepatocytes. After the 3-h incubation period, hepatocytes were washed with fresh culture media to remove non-invaded sporozoites and cells were incubated at $37^{\circ} \mathrm{C}$ for $96 \mathrm{~h}$. The RNA from the cells was harvested and quantitative real-time PCR (qRT-PCR) analysis on Pf $18 \mathrm{~s}$ rRNA levels was used to determine the level of inhibition of liver stage development.

\section{Fluorospot assay}

Antigen-specific interferon (IFN)- $\gamma$, interleukin 2 (IL-2) and Tumour Necrosis Factor (TNF) cytokine-secreting T cells were quantified by Fluorospot (Ucytech Biosciences, Utrecht, Netherlands) following the manufacturer's instructions. Monkey anti-CD3 mAb (Mabtech Inc., Cincinnati, $\mathrm{OH}$ ) was used as an internal positive control. Each well contained $25 \mu \mathrm{L}$ CD28 and CD49d (BD Biosciences, San Diego, CA) cell stimulants, $25 \mu \mathrm{L}$ of antigen and $50 \mu \mathrm{L}$ of cells $\left(2.5 \times 10^{5} /\right.$ well $)$. Antigen-specific 
responses were stimulated with either recombinant FMP013 $(10 \mu \mathrm{g} / \mathrm{mL})$ or a CSP-peptide pool (16-mer peptides overlapping by 11 AA; CSP AA 97-283; $1.25 \mu \mathrm{g} /$ $\mathrm{mL}$ ). Plates were incubated at $37{ }^{\circ} \mathrm{C}, 5 \% \mathrm{CO}_{2}$, for 40 to $48 \mathrm{~h}$. Fluorospot plates were analyzed using the Autoimmun Diagnostica (AID) $\mathrm{GmbH}$ Fluorospot reader (Strassberg, Germany) equipped with filters for FITC (excitation $490 \mathrm{~nm} /$ emission $510 \mathrm{~nm}$ ) and Cy3 (excitation $550 \mathrm{~nm} /$ emission $570 \mathrm{~nm}$ ).

\section{Statistical analysis}

Local reactions were scored on $0-3$ scale and significant increase above 0 was determined by a one-tailed one sample $t$-test. Systemic reactions were compared by ANOVA followed by Dunnett's correction for multiple comparisons. ELISA data were log transformed and multiple comparisons were made by ANOVA with p-values corrected by Tukey's method (GraphPad Prism software, La Jolla, CA). Statistically significant difference in group means was indicated in figures as $* * * *(p<0.0001)$, **** $(\mathrm{p}<0.001)$, *** $(\mathrm{p}<0.01)$, or * $(\mathrm{p}<0.05)$. Positive T-cell response was determined by an unpaired T-test against the respective pre-immune control.

\section{Results}

A nearly full-length soluble protein (FMP013) was used to design a study to compare toxicological, serological and cellular immunity outcomes of CSP vaccination in rhesus macaques originating from Indian and Chinese sub-populations.

\section{Local reactogenicity}

There was no sub-population specific difference between the InR and ChR with respect to the systemic and local reactions to the FMP013 formulated in ALFQ. Specifically, animal body weights remained stable throughout the study. There were no signs of ulcers or abscesses and only minimal, skin warmth, erythema and muscle indurations were caused by three doses of FMP013 vaccine in InR or ChR (Fig. 1a, c, d). A mild and transient muscle swelling, was observed on D1, D3 after vaccination in both the InR and ChR, which resolved by D7 (Fig. 1b).

\section{Systemic toxicity}

Baseline body temperatures for all animals averaged between 100 and $102.6{ }^{\circ} \mathrm{F}$ and only one episode of fever in the ChR group $\left(>104^{\circ} \mathrm{F}\right)$ was recorded out of $36 \mathrm{vac}-$ cinations, which resolved by D7 post vaccination. Blood biochemistry parameters as well as haematological parameters at baseline were comparable between the two sub-populations. On D1, D3 and D7 post vaccination no major changes in liver or kidney function tests were recorded in $\mathrm{ChR}$ and $\mathrm{InR}$. A trend of increased creatine kinase $(\mathrm{CK})$ on $\mathrm{D} 1$ post vaccination was seen in InR and ChR (Fig. 2a), which returned back to normal levels by D7. Blood cell count showed RBC, reticulocyte, and lymphocytes remained stable. Platelets trended to be higher by $\mathrm{D} 7$ post vaccination in both groups, although this rise was not significant and resolved prior to the next vaccine time-point. There was an increase in white blood cell, monocyte and neutrophil cell counts on D1 post vaccination (Fig. 2b-d). All cell count elevations were replicated by $\operatorname{InR}$ and $C h R$ and these values returned back to normal by D7. Overall, InR and ChR showed no difference in local or systemic adverse events following three doses of FMP013 vaccine formulated in ALFQ.

\section{Antibody titer and function}

To compare the kinetics of induction of antibodies, group mean titers were compared between sub-populations over the course of vaccination. An ELISA against FMP013 coat antigen (Fig. 3a) and the NPNA repeat peptide (Fig. $3 \mathrm{~b}$ ) showed that all animals seroconverted following the first dose and subsequent vaccinations boosted titers. The titers against the FMP013 antigen were identical in the two sub-populations over time (Fig. 3a). However, there was a trend towards slower acquisition of antibodies in the ChR group against the NPNA repeat region (Fig. 3b). The InR group mean NPNA-specific titer at 2 weeks post first dose (19,036 vs. 7819), 4 weeks post first dose $(20,468$ vs. 7070$)$ and 4 weeks post second dose $(36,631$ vs. 18,201$)$, were higher than the ChR group (Fig. 3b). These differences in titer were however not statistically significant, and NPNA titer in both models reached near equivalence after the third dose $(38,571$ vs. 41,066). NPNA ELISA titers at 2 weeks post third dose were statistically equivalent between the two subpopulations (Fig. 3c), but the NPNA-specific avidity was higher in the ChR model (Fig. 3d). P. falciparum does not infect rhesus macaques and there are no transgenic parasites available to challenge rhesus monkeys. Instead, an in vitro inhibition of liver stage development assay (ILSDA) was used to compare antibody function. As was seen with avidity, the ILSDA activity, at 1:200 dilution, for FMP013 induced antibodies was higher in the ChR group than in InR (Fig. 3e). At 1:300 serum dilution the inhibition levels in both InR and ChR groups were $<5 \%$ (not plotted).

\section{T-cell activity}

PBMCs collected at 4 weeks post 3 rd vaccine were stimulated with either the FMP013 protein or a CSP peptide pool that spans the repeats, $\mathrm{N}$ - and $\mathrm{C}$-terminal regions (Fig. 4). InR and $\mathrm{ChR}$ both showed IFN- $\gamma$ responses 


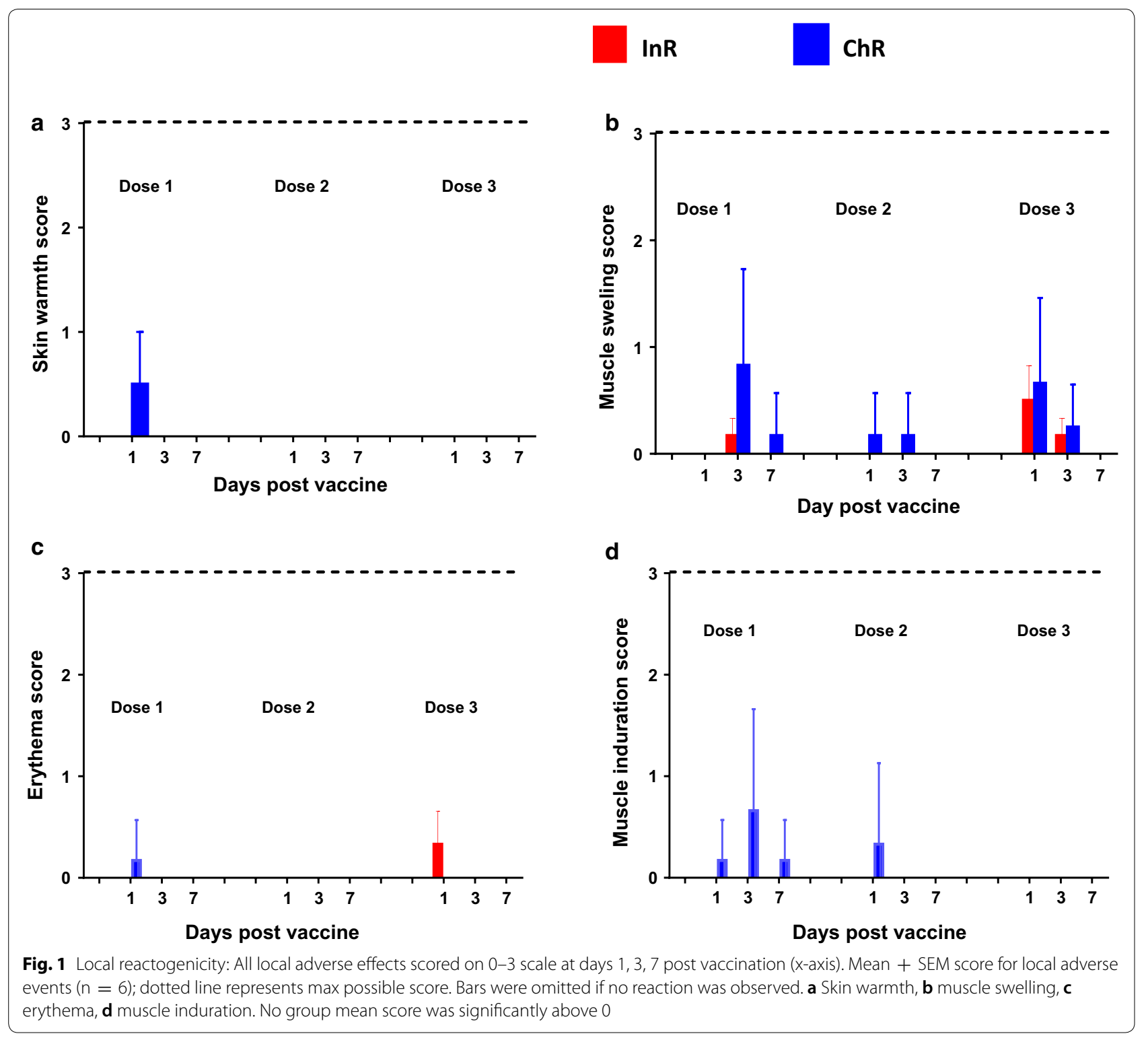

above pre-immune controls which were elicited by the FMP013 vaccine. Likewise, FMP013 vaccine induced IL-2 responses in both $\mathrm{ChR}$ and InR that could be recalled more readily by stimulating with the FMP013, but not the peptide pool, showing similar T-epitope usage by the two models. No TNF responses were observed. Overall, InR and ChR closely replicated the T-cell responses elicited by the FMP013 vaccine.

\section{Discussion}

Mouse, rabbit and rhesus models have been used to down-select and predict immunogenicity and functional outcomes of malaria vaccine candidates. While mouse and rabbit models have not been good predictors of malaria vaccine success in humans [31-34], the rhesus model played a key role in the development and improvement of the most advanced malaria vaccine RTS,S/AS01. A preliminary study in InR led to switching the adjuvant for RTS,S to AS01B in humans $[29,35,36]$. Another rhesus study in InR showed that priming RTS,S with a dose of adenovirus vectored CSP could augment CD4+ cellular responses, which was subsequently reproduced in humans $[37,38]$. There is evidence to suggest that HLA genotype may influence RTS,S-mediated protective efficacy [39]. While InR have been most widely employed for vaccine studies, functional characterization of the 


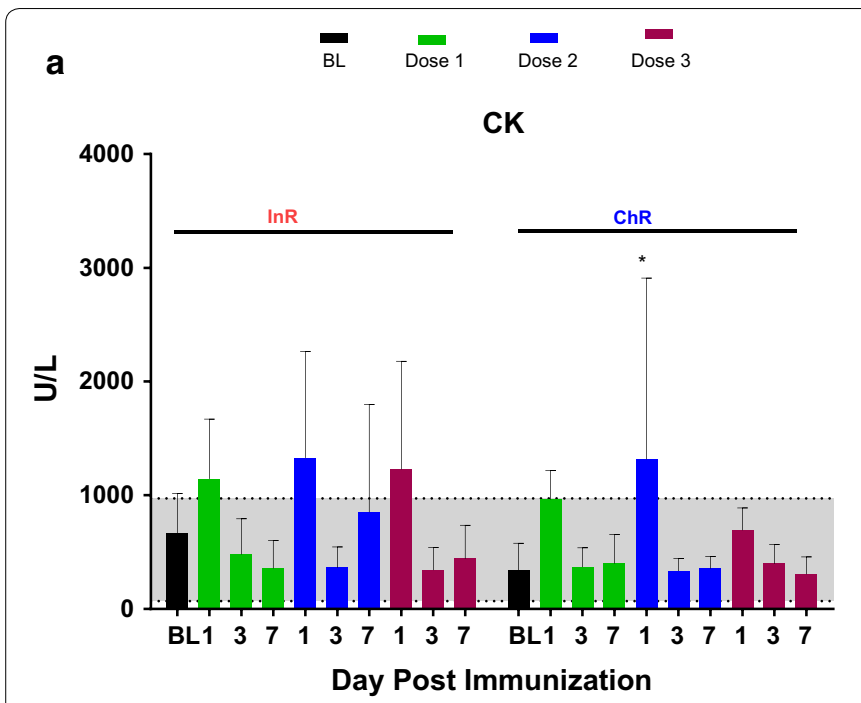

b

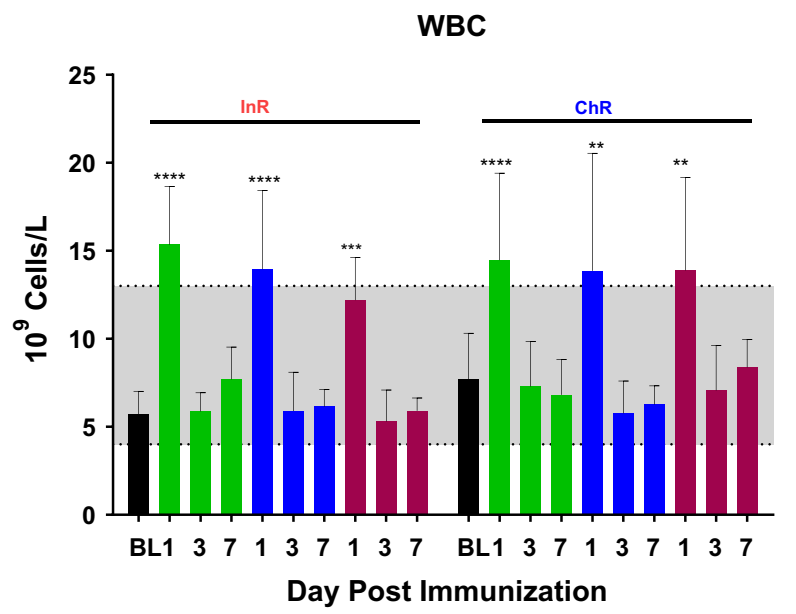

c

Monocytes

d Neutrophils
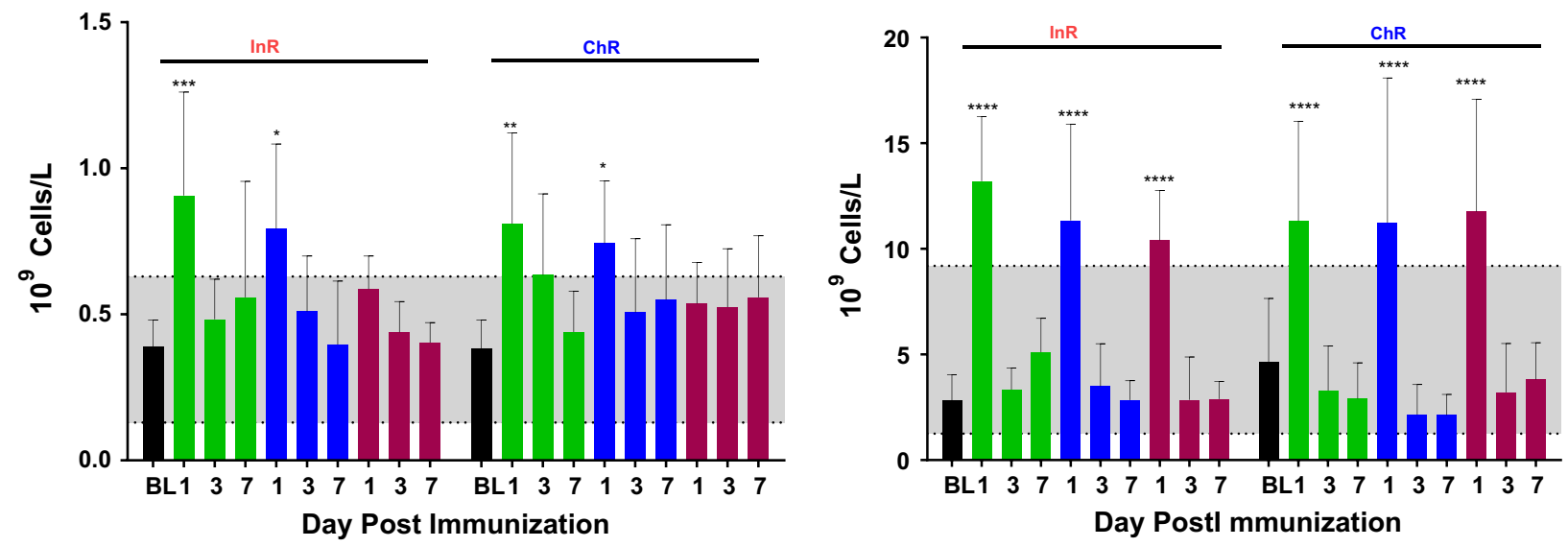

Fig. 2 Systemic toxicity: mean + SEM values for blood chemistry and complete blood count on days 1, 3, 7 ( $n=6)$. 1st, 2nd and 3rd vaccine doses are shown in green, blue and red bars respectively. Mean baseline (BL) for each group and reference range is shaded area. $\mathbf{a}$ Creatine kinase (CK), $\mathbf{b}$ WBC, c monocytes and $\mathbf{d}$ neutrophils

most common MHC class I allele among disparate ChR (Mamu-A1*02201), shows a significant overlap with the peptide binding repertoire of HLA-B7, the most frequent supertype in human populations [40]. ChR may at least as good if not better than InR for testing malaria vaccines. Indeed, $\mathrm{ChR}$ are increasingly utilized to study human pathogenic viruses like Marburg, Ebola, influenza and HIV [27, 41-45].

In order to study if responses to a malaria vaccine CSP in the InR model differed significantly from the ChR subpopulation, a nearly full-length soluble protein (FMP013) adjuvanted with a liposomal adjuvant ALFQ was tested in the InR and ChR models. The two rhesus models had similar baseline haematology and biochemistry parameters; both models replicated a mild local and systemic adverse reaction to the vaccines, characterized by an elevation of CK (2000-5000 IU/L), transient neutrophilia and monocytosis. Elevation of CK has been indicated in striated muscle damage and co-elevation of neutrophils and monocytes are markers of systemic inflammation known to be associated with the administration of QS-21 containing adjuvants $[29,46]$. These observations established that the FMP013/ALFQ vaccine was safe and that $\mathrm{ChR}$ and InR could closely replicate toxicological effects of vaccines.

FMP013 induced T-cell response and ELISA titer were similar in InR and ChR. However, vaccine-induced NPNA antibody titers increased more gradually in the ChR model and after the final vaccine dose, antibodies in the ChR group had higher NPNA-specific avidity 

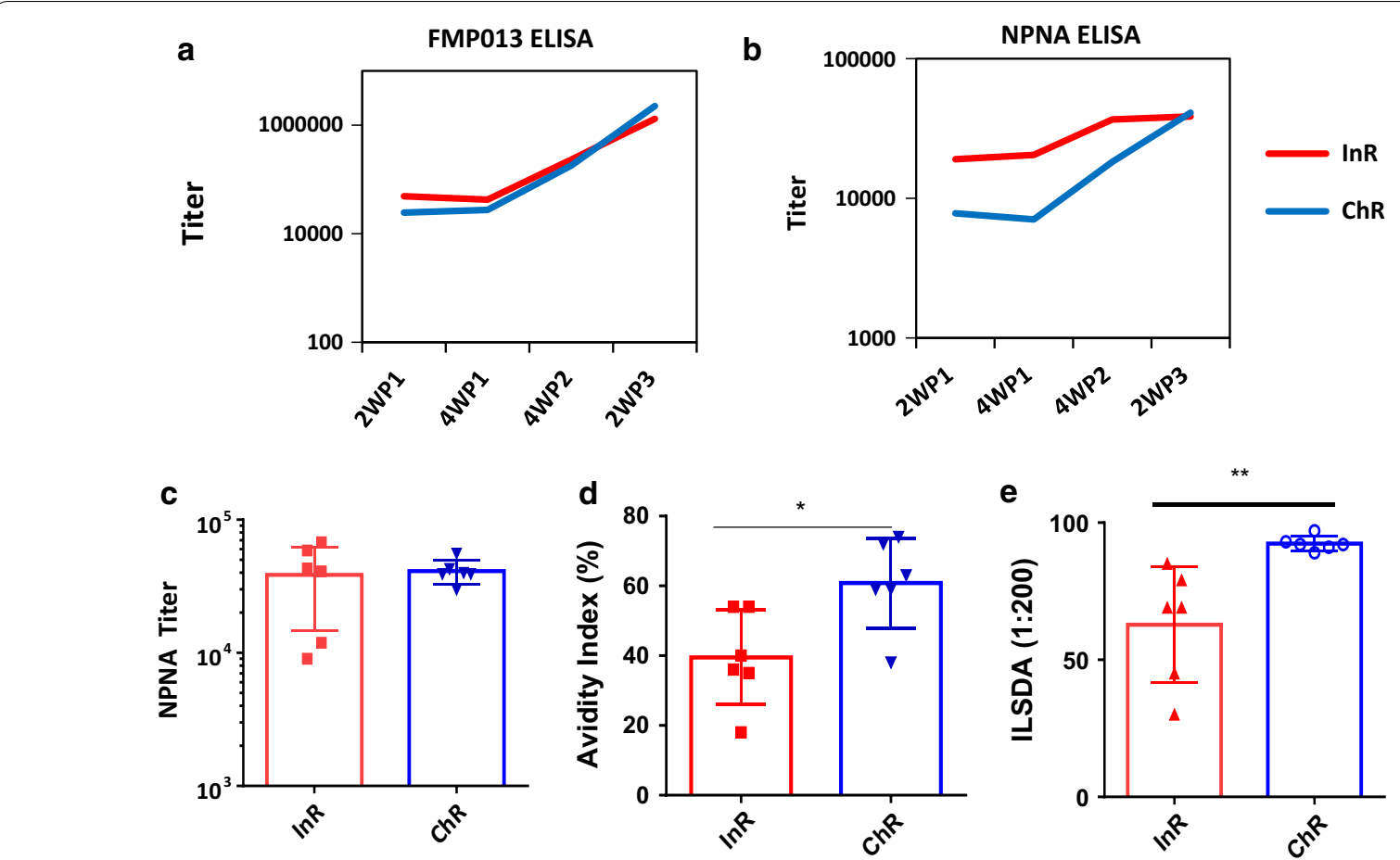

Fig. 3 Antibody titer and function: mean ELISA titers at 2 weeks post 1st (2WP1), 4WP1, 4WP2 and 2WP3 against, a FMP013 antigen; b (NANP) 6 repeat antigen. Individual animal and at 2 weeks post 3rd dose showing; c NPNA ELISA titers; d NPNA antibody avidity index; e inhibition of liver stage development (ILSDA) assay performed at 1:200 serum dilution (4 replicates per sample). Bars represent group mean \pm SEM $(n=6)$

and higher ILSDA activity than the InR model. Avidity of CSP antibodies has been associated with protection [30] and inhibition of sporozoite invasion by repeat-specific antibodies is believed to be critical for RTS,S mediated protection [47]. The observed differences in antibody responses between $\mathrm{ChR}$ and InR were not associated with the sex or weight of the animals. It cannot be completely rule out that the imported ChR used in this study had been naturally exposed to simian malaria and the observed difference in humoral response between InR and $\mathrm{ChR}$ was due to a pre-existing anti-malaria immunity in wild-caught ChR. It is notable that two independent HIV/SIV studies have also reported superior antibody titers and neutralizing activity were elicited in the ChR model $[24,45]$. Due to the small sample size $(n=6)$, future studies with other CSP vaccines are needed to definitively establish if the two sub-populations of rhesus truly differ in their response to the repeat epitope of CSP.

The frontline CSP vaccine, RTS,S, is a particulate antigen, expressed in yeast and it contains only the major repeats and the C-terminal region of CSP. In contrast, FMP013 is nearly full-length, soluble protein, expressed in E. coli, and it contains key $\mathrm{N}$-terminal and junctional epitopes that are not present in RTS,S $[48,49]$. In mice and two sub-populations of rhesus, FMP013/ALFQ vaccine was found safe and it elicited antibody, T-cell responses that have been associated with RTS,S-mediated protection [10, 11, 35]. Positive outcome of a CHMI trial with FMP013/ALFQ vaccine can establish if epitope broadening can augment CSP vaccine efficacy [50]; if soluble proteins can still be considered a viable vaccine platform against malaria [51]; and provide the first evidence of safety and potency of a novel adjuvant ALFQ in humans [12].

\section{Conclusions}

As new paradigms of vaccinology emerge, rhesus model can play a pivotal role in accelerating and de-risk preclinical selection of CSP-based vaccines, where comparison to a benchmark can be used to select improved vaccines. Based on comparisons to historical data on RTS,S/AS01, WRAIR Malaria Vaccine Branch has utilized an InR immunogenicity study to transition the FMP013/ALFQ 


\section{a}

Stimulant FMP 013

IFN- $\gamma$

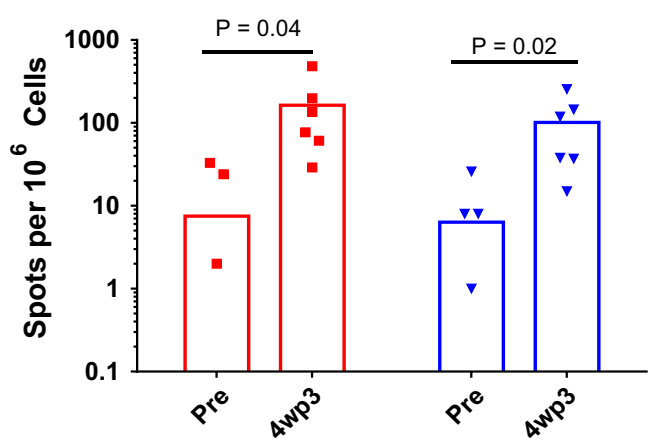

Stimulant FMP 013

IL-2

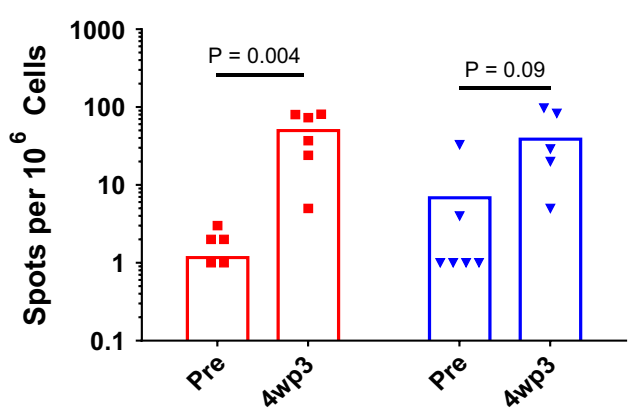

Stimulant FMP 013

TNF- $\alpha$

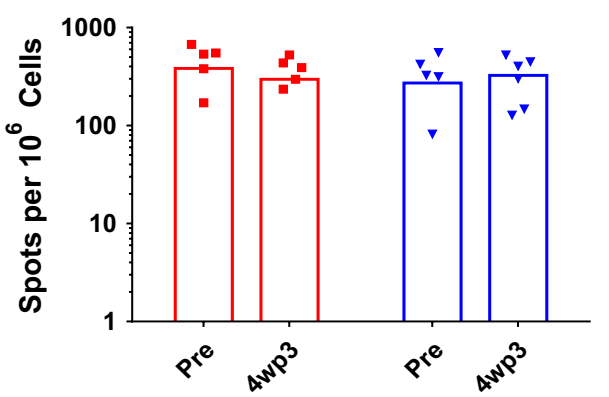

b

Stimulant peptide pool
IFN- $\gamma$

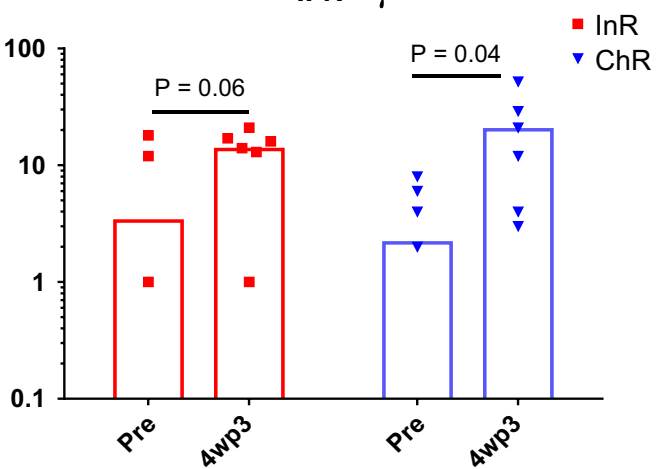

Stimulant peptide pool

IL-2

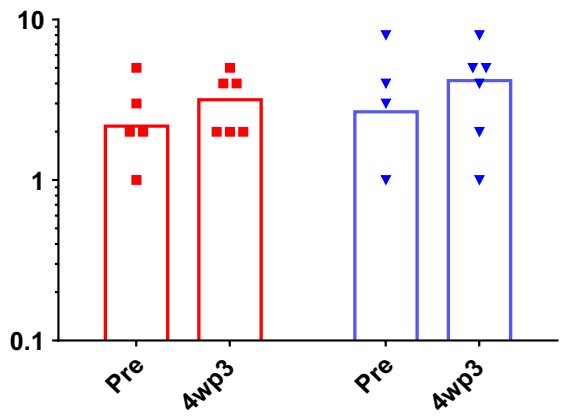

Stimulant peptide pool

TNF- $\alpha$

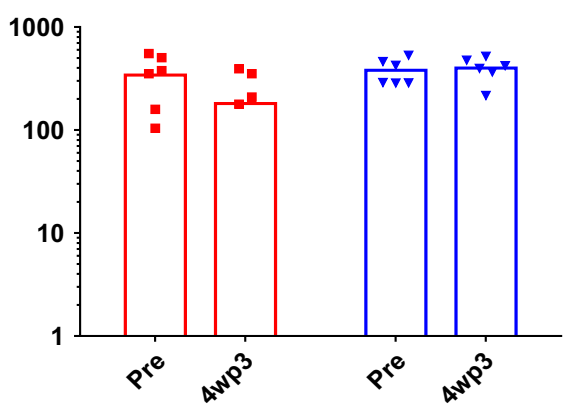

Fig. 4 T-cell activity: at 4 weeks post 3rd vaccination T-cell responses induced by FMP013 vaccination were measured in InR and ChR by IFN- $\gamma$, IL-2 and TNF-a Flourospot assay. Rhesus PBMCs were stimulated with either a FMP013 antigen or $\mathbf{b}$ a pool of peptides spanning the full length CSP sequence. Bars represent mean + SEM spots formed per million cells $(n=6)$

vaccine to a Phase I human trial [10]. Keeping in mind some differences in antibody quality reported here, InR and ChR macaques could be used inter-changeably as a valid model for conducting down-selection studies.

\section{Supplementary information}

Supplementary information accompanies this paper at https://doi. org/10.1186/s12936-019-3014-5
Additional file 1: Table S1. Sex, weight and birthdate of all rhesus used within the study. Table S2A, B. Mean Blood Counts and Blood Chemistry data across each group on days 1, 3,7 post vaccination.

\section{Abbreviations}

CSP: circumsporozoite protein; FMP013: falciparum malaria protein-013 comprising of CSP; ALFQ: army liposomal formulation containing QS21; InR: Indian origin rhesus macaques; ChR: Chinese origin rhesus macaques; WRAIR: Walter Reed Army Institute of Research. 


\section{Acknowledgements}

We thank Lorraine Soisson and Carter Diggs, USAID Malaria Vaccine Program for their advice and guidance and manuscript review. We thank COL Viseth Ngauy, Malaria Biologics Branch for manuscript review. We thank the WRAIR Malaria Serology Lab for conducting the ELISA. We thank Sri Hadiwidjojo for help in conducting the ILSDA. We thank and LTC Christian Hofer for critical review of the manuscript and the staff of the Veterinary Service Program for assistance with rhesus handling.

\section{Authors' contributions}

SD, MLM, AS, AAB designed the study; MLM and AS conducted the rhesus study; MLM, SD, AAB wrote the paper; ESBL conducted T-cell work; XZ conducted ILSDA; KS assisted in the immunological analysis; ZB and GRM produced the adjuvant. All authors read and approved the final manuscript.

\section{Funding}

The funding for this research was provided by the USAID Malaria Vaccine Development Program (Grant number: Inter-Agency Agreement) and the Department of the Army. The funding bodies had no role in the design of the study and collection, analysis, and interpretation of data and in writing the manuscript.

\section{Availability of data and materials}

The datasets used and/or analyzed during the current study are available from the corresponding author at a reasonable request.

\section{Ethics approval and consent to participate}

Research was conducted under an IACUC-approved animal use protocol in a AAALAC International accredited facility in compliance with the Animal Welfare Act and other federal statutes and regulations relating to animals and experiments involving animals and adheres to principles stated in the eighth edition, Guide for the Care and Use of Laboratory Animals, NRC Publication, 2011 edition.

\section{Consent for publication}

Material has been reviewed by the Walter Reed Army Institute of Research and the US Agency for Internationals Development. There is no objection to its presentation and/or publication. The opinions or assertions contained herein are the private views of the authors, and are not to be construed as official, or as reflecting true views of the Department of the Army, the Department of Defense, or the US Agency for International Development.

\section{Competing interests}

SD has a patent on the FMP013. ZB, SD and GRM have filed patents on the ALFQ formulation of FMP013.

\section{Author details}

${ }^{1}$ Division of Veterinary Medicine, Walter Reed Army Institute of Research, Silver Spring, MD 20910, USA. ${ }^{2}$ Structural Biologics Laboratory, Malaria Biologics Branch, Walter Reed Army Institute of Research, Silver Spring, MD 20910, USA. ${ }^{3}$ Immunology Core, Malaria Biologics Branch, Walter Reed Army Institute of Research, Silver Spring, MD 20910, USA. ${ }^{4}$ Malaria Department, Naval Medical Research Center, Silver Spring, MD 20910, USA. ${ }^{5}$ Military HIV Research Program, Walter Reed Army Institute of Research, Silver Spring, MD 20910, USA. ${ }^{6}$ Henry M. Jackson Foundation, Rockville, MD 20852, USA.

Received: 29 August 2019 Accepted: 18 November 2019 Published online: 27 November 2019

\section{References}

1. WHO. World malaria report 2017. Geneva: World Health Organization; 2017. p. 196.

2. White NJ, Pukrittayakamee S, Hien TT, Faiz MA, Mokuolu OA, Dondorp AM. Malaria. Lancet. 2014;383:723-35.

3. Garcon N, Heppner DG, Cohen J. Development of RTS,S/AS02: a purified subunit-based malaria vaccine candidate formulated with a novel adjuvant. Expert Rev Vaccines. 2003;2:231-8.
4. Agnandji ST, Fernandes JF, Bache EB, Ramharter M. Clinical development of RTS,S/AS malaria vaccine: a systematic review of clinical Phase I-III trials. Future Microbiol. 2015;10:1553-78.

5. Neafsey DE, Juraska M, Bedford T, Benkeser D, Valim C, Griggs A, et al. Genetic diversity and protective efficacy of the RTS,S/AS01 malaria vaccine. N Engl J Med. 2015:373:2025-37.

6. White MT, Verity R, Griffin JT, Asante KP, Owusu-Agyei S, Greenwood B, et al. Immunogenicity of the RTS,S/AS01 malaria vaccine and implications for duration of vaccine efficacy: secondary analysis of data from a phase 3 randomised controlled trial. Lancet Infect Dis. 2015;15:1450-8.

7. RTS,S Clinical Trials Partnership. Efficacy and safety of the RTS,S/AS01 malaria vaccine during 18 months after vaccination: a phase 3 randomized, controlled trial in children and young infants at 11 African sites. PLoS Med. 2014;11:e1001685.

8. Adepoju P. RTS,S malaria vaccine pilots in three African countries. Lancet. 2019;393:1685.

9. Schwenk R, DeBot M, Porter M, Nikki J, Rein L, Spaccapelo R, et al. IgG2 antibodies against a clinical grade Plasmodium falciparum CSP vaccine antigen associate with protection against transgenic sporozoite challenge in mice. PLoS ONE. 2014;9:e111020.

10. Cawlfield A, Genito CJ, Beck Z, Bergmann-Leitner ES, Bitzer AA, Soto K, et al. Safety, toxicity and immunogenicity of a malaria vaccine based on the circumsporozoite protein (FMP013) with the adjuvant army liposome formulation containing QS21 (ALFQ). Vaccine. 2019;37:3793-803.

11. Genito CJ, Beck Z, Phares TW, Kalle F, Limbach KJ, Stefaniak ME, et al. Liposomes containing monophosphoryl lipid A and QS-21 serve as an effective adjuvant for soluble circumsporozoite protein malaria vaccine FMP013. Vaccine. 2017;35:3865-74.

12. Beck Z, Matyas GR, Jalah $R$, Rao M, Polonis VR, Alving CR. Differential immune responses to HIV-1 envelope protein induced by liposomal adjuvant formulations containing monophosphoryl lipid A with or without QS21. Vaccine. 2015;33:5578-87.

13. Kaslow DC, Biernaux S. RTS,S: toward a first landmark on the Malaria Vaccine Technology Roadmap. Vaccine. 2015;33:7425-32.

14. Porter MD, Nicki J, Pool CD, DeBot M, Illam RM, Brando C, et al. Transgenic parasites stably expressing full-length Plasmodium falciparum circumsporozoite protein as a model for vaccine down-selection in mice using sterile protection as an endpoint. Clin Vaccine Immunol. 2013;20:803-10.

15. Phares TW, May AD, Genito CJ, Hoyt NA, Khan FA, Porter MD, et al. Rhesus macaque and mouse models for down-selecting circumsporozoite protein based malaria vaccines differ significantly in immunogenicity and functional outcomes. Malar J. 2017;16:115.

16. Bimber BN, Ramakrishnan R, Cervera-Juanes R, Madhira R, Peterson SM, Norgren RB Jr, et al. Whole genome sequencing predicts novel human disease models in rhesus macaques. Genomics. 2017;109:214-20.

17. Karl JA, Wiseman RW, Campbell KJ, Blasky AJ, Hughes AL, Ferguson B, et al. Identification of MHC class I sequences in Chinese-origin rhesus macaques. Immunogenetics. 2008;60:37-46.

18. Ferguson B, Street SL, Wright H, Pearson C, Jia Y, Thompson SL, et al. Single nucleotide polymorphisms (SNPS) distinguish Indian-origin and Chinese-origin rhesus macaques (Macaca mulatta). BMC Genomics. 2007;8:43.

19. Clarke MR, O'Neil JA. Morphometric comparison of Chinese-origin and Indian-derived rhesus monkeys (Macaca mulatta). Am J Primatol. 1999:47:335-46.

20. Kanthaswamy S, Johnson Z, Trask JS, Smith DG, Ramakrishnan R, Bahk J, et al. Development and validation of a SNP-based assay for inferring the genetic ancestry of rhesus macaques (Macaca mulatta). Am J Primatol. 2014;76:1105-13.

21. Champoux M, Higley JD, Suomi SJ. Behavioral and physiological characteristics of Indian and Chinese-Indian hybrid rhesus macaque infants. Dev Psychobiol. 1997;31:49-63.

22. Smith DG, McDonough J. Mitochondrial DNA variation in Chinese and Indian rhesus macaques (Macaca mulatta). Am J Primatol. 2005;65:1-25.

23. Liao Q, Strong AJ, Liu Y, Liu Y, Meng P, Fu Y, et al. HIV vaccine candidates generate in vitro $T$ cell response to putative epitopes in Chinese-origin rhesus macaques. Vaccine. 2012;30:1601-8.

24. Stahl-Hennig C, Suh YS, Park KS, Sauermann U, Kim KS, Ahn S, et al. Immunogenicity of a DNA prime and recombinant adenovirus boost regime significantly varies between rhesus macaques of Chinese and Indian origins. J Med Primatol. 2007;36:195-205. 
25. Marcondes MC, Penedo MC, Lanigan C, Hall D, Watry DD, Zandonatti M, et al. Simian immunodeficiency virus-induced CD4+ T cell deficits in cytokine secretion profile are dependent on monkey origin. Viral Immunol. 2006;19:679-89.

26. Marthas ML, Lu D, Penedo MC, Hendrickx AG, Miller CJ. Titration of an SIVmac251 stock by vaginal inoculation of Indian and Chinese origin rhesus macaques: transmission efficiency, viral loads, and antibody responses. AIDS Res Hum Retrov. 2001;17:1455-66.

27. Degenhardt JD, de Candia P, Chabot A, Schwartz S, Henderson L, Ling B, et al. Copy number variation of CCL3-like genes affects rate of progression to simian-AIDS in Rhesus Macaques (Macaca mulatta). PLoS Genet. 2009;5:e1000346.

28. Zhou Y, Bao R, Haigwood NL, Persidsky Y, Ho WZ. SIV infection of rhesus macaques of Chinese origin: a suitable model for HIV infection in humans. Retrovirology. 2013;10:89.

29. Stewart VA, McGrath SM, Walsh DS, Davis S, Hess AS, Ware LA, et al. Preclinical evaluation of new adjuvant formulations to improve the immunogenicity of the malaria vaccine RTS,S/AS02A. Vaccine. 2006;24:6483-92.

30. Regules JA, Cicatelli SB, Bennett JW, Paolino KM, Twomey PS, Moon JE, et al. Fractional third and fourth dose of RTS,S/AS01 malaria candidate vaccine: a phase 2 a controlled human malaria parasite infection and immunogenicity study. J Infect Dis. 2016;214:762-71.

31. Heppner DG Jr, Kester KE, Ockenhouse CF, Tornieporth N, Ofori O, Lyon $J A$, et al. Towards an RTS,S-based, multi-stage, multi-antigen vaccine against falciparum malaria: progress at the Walter Reed Army Institute of Research. Vaccine. 2005;23:2243-50.

32. Wang R, Charoenvit Y, Corradin G, De La Vega P, Franke ED, Hoffman SL. Protection against malaria by Plasmodium yoelii sporozoite surface protein 2 linear peptide induction of CD4+ T cell- and IFN-gamma-dependent elimination of infected hepatocytes. J Immunology. 1996;157:4061-7.

33. Lynch MM, Cernetich-Ott A, Weidanz WP, Burns JM Jr. Prediction of merozoite surface protein 1 and apical membrane antigen 1 vaccine efficacies against Plasmodium chabaudi malaria based on prechallenge antibody responses. Clin Vaccine Immunol. 2009;16:293-302.

34. Anders RF, Crewther PE, Edwards S, Margetts M, Matthew ML, Pollock B, et al. Immunisation with recombinant AMA-1 protects mice against infection with Plasmodium chabaudi. Vaccine. 1998;16:240-7.

35. Kester KE, Cummings JF, Ofori-Anyinam O, Ockenhouse CF, Krzych U, Moris P, et al. Randomized, double-blind, phase 2a trial of falciparum malaria vaccines RTS,S/AS01B and RTS,S/AS02A in malaria-naive adults: safety, efficacy, and immunologic associates of protection. J Infect Dis. 2009;200:337-46.

36. Polhemus ME, Remich SA, Ogutu BR, Waitumbi JN, Otieno L, Apollo S, et al. Evaluation of RTS,S/ASO2A and RTS,S/AS01B in adults in a high malaria transmission area. PLOS ONE. 2009;4:e6465.

37. Stewart VA, McGrath SM, Dubois PM, Pau MG, Mettens P, Shott J, et al. Priming with an adenovirus 35-circumsporozoite protein (CS) vaccine followed by RTS,S/ASO1B boosting significantly improves immunogenicity to Plasmodium falciparum CS compared to that with either malaria vaccine alone. Infect Immun. 2007;75:2283-90.

38. Ockenhouse CF, Regules J, Tosh D, Cowden J, Kathcart A, Cummings J, et al. Ad35.CS.01-RTS,S/AS01 heterologous prime boost vaccine efficacy against sporozoite challenge in healthy malaria-naive adults. PLoS ONE. 2015;10:e0131571.
39. Nielsen CM, Vekemans J, Lievens M, Kester KE, Regules JA, Ockenhouse CF. RTS,S malaria vaccine efficacy and immunogenicity during Plasmodium falciparum challenge is associated with HLA genotype. Vaccine. 2018;36:1637-42.

40. Solomon C, Southwood S, Hoof I, Rudersdorf R, Peters B, Sidney J, et al. The most common Chinese rhesus macaque MHC class I molecule shares peptide binding repertoire with the HLA-B7 supertype. Immunogenetics. 2010;62:451-64.

41. Geisbert TW, Daddario-DiCaprio KM, Geisbert JB, Young HA, Formenty P, Fritz EA, et al. Marburg virus Angola infection of rhesus macaques: pathogenesis and treatment with recombinant nematode anticoagulant protein C2. J Infect Dis. 2007;196(Suppl 2):S372-81.

42. Larsen T, Stevens EL, Davis KJ, Geisbert JB, Daddario-DiCaprio KM, Jahrling $\mathrm{PB}$, et al. Pathologic findings associated with delayed death in nonhuman primates experimentally infected with Zaire Ebola virus. I Infect Dis. 2007;196(Suppl 2):S323-8.

43. Carroll TD, Matzinger SR, Genesca M, Fritts L, Colon R, McChesney MB, et al. Interferon-induced expression of MxA in the respiratory tract of rhesus macaques is suppressed by influenza virus replication. J Immunol. 2008;180:2385-95.

44. Ling B, Veazey RS, Hart M, Lackner AA, Kuroda M, Pahar B, et al. Early restoration of mucosal CD4 memory CCR5 T cells in the gut of SIV-infected rhesus predicts long term non-progression. AIDS. 2007;21:2377-85.

45. Ling B, Veazey RS, Luckay A, Penedo C, Xu K, Lifson JD, et al. SIV(mac) pathogenesis in rhesus macaques of Chinese and Indian origin compared with primary HIV infections in humans. AIDS. 2002;16:1489-96.

46. Pichyangkul S, Tongtawe P, Kum-Arb U, Yongvanitchit K, Gettayacamin $M$, Hollingdale MR, et al. Evaluation of the safety and immunogenicity of Plasmodium falciparum apical membrane antigen 1, merozoite surface protein 1 or RTS,S vaccines with adjuvant system AS02A administered alone or concurrently in rhesus monkeys. Vaccine. 2009;28:452-62.

47. Oyen D, Torres JL, Wille-Reece U, Ockenhouse CF, Emerling D, Glanville J, et al. Structural basis for antibody recognition of the NANP repeats in Plasmodium falciparum circumsporozoite protein. Proc Natl Acad Sci USA. 2017;114:E10438-e45.

48. Espinosa DA, Gutierrez GM, Rojas-Lopez M, Noe AR, Shi L, Tse SW, et al. Proteolytic cleavage of the Plasmodium falciparum circumsporozoite protein is a target of protective antibodies. J Infect Dis. 2015;212:1111-9.

49. Kisalu NK, Idris AH, Weidle C, Flores-Garcia Y, Flynn BJ, Sack BK, et al. A human monoclonal antibody prevents malaria infection by targeting a new site of vulnerability on the parasite. Nat Med. 2018;24:408-16.

50. Wardemann $\mathrm{H}$, Murugan R. From human antibody structure and function towards the design of a novel Plasmodium falciparum circumsporozoite protein malaria vaccine. Curr Opin Immunol. 2018;53:119-23.

51. Dendouga N, Fochesato M, Lockman L, Mossman S, Giannini SL. Cell-mediated immune responses to a varicella-zoster virus glycoprotein E vaccine using both a TLR agonist and QS21 in mice. Vaccine. 2012;30:3126-35.

\section{Publisher's Note}

Springer Nature remains neutral with regard to jurisdictional claims in published maps and institutional affiliations.
Ready to submit your research? Choose BMC and benefit from:

- fast, convenient online submission

- thorough peer review by experienced researchers in your field

- rapid publication on acceptance

- support for research data, including large and complex data types

- gold Open Access which fosters wider collaboration and increased citations

- maximum visibility for your research: over $100 \mathrm{M}$ website views per year

At $\mathrm{BMC}$, research is always in progress.

Learn more biomedcentral.com/submissions 